\title{
ASPECTOS ENTOACIONAIS NO DESENVOLVIMENTO DA FALA INFANTIL DA VARIEDADE MINEIRA DO PB
}

\author{
INTONATIONAL ASPECTS ON SPEECH DEVELOPMENT OF BRAZILIAN \\ PORTUGUESE SPEAKING CHILDREN FROM THE STATE OF MINAS GERAIS
}

\author{
Andressa Christine Oliveira da Silva | Lattes | andressa.silva@letras.uff.br \\ Universidade Federal de Juiz de Fora | FAPEMIG
}

\author{
Aline Alves Fonseca | Lattes | alineafonseca@gmail.com \\ Universidade Federal de Juiz de Fora
}

\author{
Sara de Oliveira Gomes Barreto | Lattes | sarinhapsi@yahoo.com.br \\ Universidade Salgado de Oliveira
}

Resumo: Neste trabalho, analisamos o padrão entoacional da fala de 3 crianças mineiras, com idades entre 5:9 e 6:8 anos, naturais de Juiz de Fora, falantes de Português Brasileiro (PB), a partir de questionários que simulavam situações conversacionais, nos moldes metodológicos de Frota et al. (2015). O objetivo foi investigar os contornos prosódicos padrão entoacional, proeminência e ritmo - utilizados por elas e compará-los aos padrões entoacionais de falantes adultos da variedade mineira do $\mathrm{PB}$, descritos no Interactive Atlas of Romance Intonation (PRIETO et al., 2010-2014). Os resultados das análises sugerem que as crianças adquirem os padrões entoacionais de forma gradativa, assim como adquirem os segmentos, as palavras e as estruturas sintáticas da língua.

Palavras-chave: Fonologia entoacional; Fala infantil; Português brasileiro; Variedade mineira.

\begin{abstract}
In this paper, we analyzed the intonational speech pattern of three children, who were born in the city of Juiz de Fora, state of Minas Gerais, are native speakers of Brazilian Portuguese (BP) and whose ages ranged from 5:9 to 6:8 years old. Thus, based on Frota et al. (2015), questionnaires, which simulated ordinary conversational situations, were administered to the children in order to investigate the prosodic contours - intonational pattern, prominence and rhythm - used by those three children and compare them with the intonational patterns of adult speakers of the same dialect, which are described in
\end{abstract}


the Interactive Atlas of Romance Intonation (PRIETO et al., 2010-2014). Results of the present study indicate that children acquire the intonational patterns gradually, as they acquire the segments, words and syntactic structures of their native language.

Keywords: Intonational phonology; Child speech; Brazilian Portuguese; Minas Gerais dialect.

\section{Introdução}

Neste artigo, examinou-se o contorno prosódico utilizado por 3 crianças juiz-foranas, entre 5:9 e 6:8 anos, falantes do Português Brasileiro (doravante PB) na variedade mineira. O nosso objetivo foi verificar se essas crianças já apresentam, em sua fala, padrões entoacionais semelhantes aos de falantes adultos da variedade mineira do $\mathrm{PB}$, descritos no Interactive Atlas of Romance Intonation (PRIETO et al., 2010-2014). A escolha da faixa etária das crianças participantes da investigação se justifica pelo fato de contemplar a fase final do período de aquisição fonológica da linguagem (LAMPRECHT et al., 2004).

O trabalho de Frota et al. (2015) constituiu a base para nosso estudo, tanto do ponto de vista teórico, quanto do metodológico. O estudo desenvolvido pela equipe de pesquisadores portugueses e brasileiros faz parte de um projeto de criação do Atlas Prosódico Interativo das Línguas Românicas: Francês, Catalão, Friulano, Italiano, Occitano, Português, Romeno, Sardo e Espanhol (PRIETO et al., 2010-2014). Para a comparação dos contornos entoacionais infantil e adulto, conduzida nesta pesquisa, utilizaremos o estudo do padrão entoacional das variedades do Português Europeu e do Português Brasileiro, realizado por Frota e colaboradores (2015), que investigou contornos nucleares e padrões entoacionais de fraseamento em diferentes situações comunicativas, em uma perspectiva de línguas românicas, com o método indutivo de elicitação de dados Discourse Completion Task (DCT).

As variedades do PB que foram investigadas por Frota et al. (2015), faladas em localidades urbanas e representativas de formas regionais do PB, são: o falar Baiano (coletado em Salvador); o Mineiro (coletado em Belo Horizonte) e o Sulista (coletados em São Paulo e em Porto Alegre). Os autores realizaram a análise do padrão entoacional de diferentes tipos frásicos, em uma ampla gama de situações discursivas, apresentadas em um questionário/entrevista, como:

- declarativas neutras e declarativas neutras com enumerações;

- declarativas não neutras (sentenças com focalização contrastiva, exclamativas, 
declarativas categóricas, dubitativas, óbvias);

- interrogativas absolutas neutras que abrangem orações de uma unidade tonal, perguntas disjuntivas sim-ou-não, enumeração com disjunção e com coordenação;

- interrogativas absolutas não neutras, como perguntas confirmatórias, perguntas confirmatórias com ênfase (tag questions) e perguntas imperativas;

- interrogativas parciais (perguntas-QU) neutras, como as perguntas portadoras de mais de uma unidade tonal e perguntas portadoras de mais de uma unidade tonal com coordenação;

- interrogativas parciais não neutras, como as perguntas imperativas;

- perguntas eco não neutras, tais como perguntas eco absolutas, perguntas eco parciais, perguntas eco disjuntivas, perguntas eco absolutas anti-expectativa e perguntas eco parciais anti-expectativa;

- imperativas que expressam ordem ou pedido e

- vocativos de chamamento inicial e de chamamento insistente.

Nós nos ativemos à realização de comparações das análises entoacionais, no contexto do PB, considerando-se, especialmente, a variedade mineira. Utilizamos, em nosso trabalho, alguns dos tipos frásicos trazidos por Frota et al. (2015) que passaram por adaptações, as quais julgamos necessárias, uma vez que o nosso objetivo foi realizar um estudo com crianças em final do processo de aquisição da linguagem. Dos 31 tipos testados por Frota et al. (2015), escolhemos apenas 16, em diferentes situações discursivas, para testarmos com as crianças. Foram escolhidas declarativas neutras; declarativas neutras com enumeração; declarativas não neutras dos tipos focalização contrastiva e exclamativa; interrogativas absolutas neutras dos tipos disjunção e disjunção com enumeração; interrogativas absolutas não neutras dos tipos pergunta confirmatória e pergunta imperativa; interrogativa parcial neutra com oração de uma unidade tonal; imperativa do tipo ordem; e vocativos. Escolhemos tais tipos frásicos por fazerem parte de situações discursivas mais presentes no cotidiano das crianças na faixa etária investigada e, por isso, serem mais facilmente elicitadas.

\section{Aporte teórico}

Não se tem dúvidas de que a prosódia é um elemento fundamental nos processos de produção e percepção das línguas naturais (TEIRA; IGOA, 2007). Na produção, a prosódia interage significativamente com outros componentes da gramática: lexicais, 
sintáticos, semânticos e pragmáticos. Na compreensão, a prosódia fornece pistas ao ouvinte para segmentar e agrupar os constituintes, de modo a interpretar o significado do enunciado e a intenção do falante, além de proporcionar informação sociolinguística relacionada aos dialetos e registros de fala, bem como sinais acerca do estado emocional do falante. Uma das funções da prosódia é a segmentação do fluxo de fala em unidades, processo conhecido como fraseamento prosódico (SERRA, 2016).

A teoria da Fonologia Prosódica (NESPOR; VOGEL, 1986) aponta que a estrutura prosódica é parcialmente determinada pela estrutura sintática. Em alguns casos, essas duas estruturas podem coincidir e, em outros casos, podem divergir. Essa divergência entre estrutura sintática e estrutura prosódica confere à prosódia um papel fundamental na organização da fala. Segundo Frota (2000), o mapeamento entre sintaxe-fonologia fornece uma representação prosódica, que é hierarquicamente organizada em constituintes prosódicos.

Na versão clássica da Fonologia Prosódica de Nespor e Vogel (1986), os constituintes prosódicos organizam-se hierarquicamente em: sílaba $(\sigma)$, pé métrico $(\Sigma)$, palavra prosódica ( $\omega$ ou PW), grupo clítico (C), sintagma fonológico ( $\phi$ ou ip), sintagma entoacional (I) e enunciado fonológico (U). Descrevemos, brevemente, somente os constituintes sintagma entoacional (I ou IP) e enunciado fonológico (U), por estes serem os constituintes mais relevantes para a presente pesquisa.

O sintagma entoacional (I) é um constituinte que se caracteriza por ser o domínio que apresenta um contorno entoacional identificável e por suas fronteiras finais coincidirem, geralmente, com posições nas quais pausas podem ser alocadas. Esse constituinte promove a interação de informações fonológicas com informações provenientes da sintaxe e da semântica. $\mathrm{O}$ enunciado fonológico $(\mathrm{U})$, por sua vez, é o maior constituinte da hierarquia prosódica, e geralmente coincide com o nó mais alto de uma árvore sintática $\left(\mathrm{X}^{\mathrm{n}}\right)$. No entanto, isso não significa dizer que o $\mathrm{U}$ seja apenas a contraparte fonológica do constituinte sintático $\mathrm{X}^{\mathrm{n}}$, uma vez que o isomorfismo entre constituinte prosódico e constituinte sintático não é obrigatório. $\mathrm{O} U$ caracteriza-se por promover a interação da fonologia com a sintaxe, a semântica e a pragmática.

No que tange à entoação, esse termo tem sido empregado como sinônimo do termo prosódia (HIRST; DI CRISTO, 1998). No entanto, a entoação deve ser tomada como parte da prosódia, sendo um componente prosódico que reflete a variação melódica dentro de um enunciado (FONSECA, 2008). Hirst e Di Cristo (1998) apontam que descrever o sistema entoacional de uma língua não é uma tarefa fácil, pois a entoação 
é uma característica universal das línguas e ao mesmo tempo é uma das características mais específicas de uma língua. A entoação é universal porque todas as línguas possuem entoação e também porque os sistemas entoacionais das línguas de diferentes origens compartilham várias funções linguísticas e paralinguísticas. No entanto, apesar do caráter universal, as características específicas do sistema entoacional de um falante também são altamente dependentes do idioma, do dialeto e até mesmo do estilo, do humor e da atitude desse falante. Os autores ainda ressaltam que é impossível descrever o sistema de entoação de uma língua sem, ao mesmo tempo, levar em conta as características prosódicas relevantes, tais como o fraseamento e o ritmo. Em outras palavras, pode-se inferir que a estrutura prosódica, de algum modo, condiciona a estrutura entoacional (SERRA, 2016). Desse modo, para fazermos as descrições entoacionais das sentenças investigadas, levamos em conta também o fraseamento em constituintes prosódicos da Teoria da Hierarquia Prosódica de Nespor e Vogel (1986).

Para a análise da estrutura entoacional das sentenças deste trabalho, seguimos o modelo Autossegmental e Métrico da Fonologia Entoacional (PIERREHUMBERT, 1980; BECKMAN; PIERREHUMBERT, 1986). O sistema de notação para a descrição dos contornos entoacionais de dados de fala oral, proposto por Pierrehumbert (1980) no inglês americano, corresponde, do ponto de vista acústico, à curva de frequência fundamental (F0). Este sistema ficou conhecido como ToBI (Tones and Break Indices). Para a notação do contorno entoacional (F0), foram propostos três tipos de tons: (i) tons de fronteira (boundary tones); (ii) acento tonal (pitch accent) e (iii) acento de sintagma (phrase accent).

Os tons de fronteira são monotonais; aparecem na margem direita do sintagma entoacional (I) e podem ser representados por $\mathrm{H} \%$ ou $\mathrm{L} \%$, onde $\mathrm{H}$ significa high (alto) e L significa low (baixo). O acento tonal, em sentenças de proeminência neutra, aparece na posição nuclear do sintagma entoacional (I) que, nas línguas de recursividade à direita, como o PB, está localizada na sílaba tônica da última palavra prosódica do I. Esse acento também pode ser $\mathrm{H}$ ou $\mathrm{L}$, dos tipos monotonal $\left(\mathrm{T}^{*}\right)$ ou bitonal $\left(\mathrm{T}^{*}+\mathrm{T}\right.$ ou $\left.\mathrm{T}+\mathrm{T}^{*}\right)$; onde o sinal * (starred tone) marca o tom central que estará alinhado com a sílaba tônica, e o sinal + liga os dois tons que formam o acento bitonal. Os acentos bitonais são formados por combinações de tons simples, podendo ser representados por $\mathrm{H}^{*}+\mathrm{L}, \mathrm{H}+\mathrm{L}^{*}, \mathrm{~L}^{*}+\mathrm{H}$ ou $\mathrm{L}+\mathrm{H}^{*}$. $\mathrm{O}$ acento de sintagma aparece na margem direita do sintagma fonológico $(\phi)$ e pode ser representando por $\mathrm{H}^{-}$ou $\mathrm{L}^{-}$. No caso do $\mathrm{PB}$, raramente utiliza-se a notação de acento de sintagma, pois, em geral, somente o acento tonal e o tom fronteira se mostram informativos prosodicamente. 
Após a proposta de Pierrehumbert, estudos posteriores foram conduzidos e, consequentemente, a teoria foi revisada e sofreu algumas adaptações. No entanto, tais modificações não invalidam a contribuição seminal deste trabalho na área da fonologia entoacional, sendo a base de notação do ToBI utilizada até os dias de hoje em análises entoacionais.

Adquirir uma língua é uma tarefa complexa, devido à natureza das línguas naturais, as quais são constituídas por um sistema que apresenta diferentes unidades - fonemas, sílabas, morfemas, palavras, frases - e que funciona de acordo com regras e/ou restrições (MATZENAUER, 2004). No entanto, esse processo é relativamente rápido, espontâneo, sem esforço e sem a necessidade de um ensino formal, devido à predisposição inata da nossa espécie para adquirir línguas, a Faculdade da Linguagem (CHOMSKY, 1965).

A aquisição de uma língua consiste na segmentação de palavras do fluxo contínuo da fala e o mapeamento dessas palavras a seus significados. Dentro deste processo de segmentação, temos a Hipótese do Bootstrapping Prosódico, a qual prevê que a criança faz uso do sistema entoacional e rítmico das línguas, desde os primeiros meses de idade, para segmentar o contínuo da fala em unidades menores (MORGAN; DEMUTH, 1996; CHRISTOPHE et al., 1997). Desse modo, uma análise puramente fonológica do fluxo da fala permite à criança iniciar a aquisição do léxico e da sintaxe de sua língua. Entretanto, a aquisição fonológica e a aquisição do padrão entoacional de sua língua materna não se dão de forma homogênea junto à aquisição do léxico e da sintaxe.

No que tange à aquisição fonológica do PB, o trabalho de Lamprecht et al. (2004) apresenta o percurso cronológico da aquisição dos diferentes segmentos e estruturas silábicas, com base em dados de fala de crianças com desenvolvimento considerado típico em relação aos aspectos linguístico, cognitivo e emocional.

Os segmentos vocálicos são os primeiros a serem adquiridos, sendo a vogal /a/ a primeira delas a ser adquirida, por volta de 1:1 anos de idade. As vogais /i/ e /u/ são adquiridas com 1:2, as vogais /e/ e /o/ com 1:3, a vogal/o/ com 1:6, e a vogal / $/$ / $\operatorname{com~1:7.~}$ Todo o sistema vocálico do português é adquirido até por volta de 1:8 anos. As plosivas e as nasais são os primeiros segmentos consonantais a serem adquiridos, e estão estabelecidos antes dos dois anos de idade. As plosivas surdas /p, t, k/ seriam adquiridas antes das sonoras $/ \mathrm{b}, \mathrm{d} /$. As autoras ainda destacam que o $/ \mathrm{g} /$ pode ser adquirido por último. Com relação às nasais, os segmentos $/ \mathrm{m}, \mathrm{n} /$ já estão adquiridos entre 1:6 e 1:8, enquanto que o / $/$ / é o último a ser estabelecido, a partir de 1:7. As fricativas seguem as plosivas e as nasais na ordem de aquisição segmental. As fricativas labiais /f, v/ são as primeiras a 
serem adquiridas, o/v/ aos 1:8 e o/f/ aos 1:9. As coronais /s, z, $\int, 3 /$ são os segmentos de aquisição mais tardia na classe das fricativas. $\mathrm{O} / \mathrm{z} /$ encontra-se adquirido aos 2:0, o/s/ aos 2:6, o / 3 / aos 2:6 e o / J / aos 2:10. As líquidas são as últimas a serem adquiridas. $\mathrm{O} / \mathrm{l} / \mathrm{e}$ a primeira líquida lateral a ser dominada pelas crianças, na posição de onset absoluto aos 2:8 e na posição de onset medial aos 3:0. A líquida lateral $/ K /$ pode ser considerada dominada somente aos 3:6. Por fim, a aquisição dos róticos, em suas diferentes posições dentro da estrutura silábica, está completa apenas aos 5:0 anos de idade.

Com relação à aquisição fonológica de estruturas silábicas, as autoras apontam que a aquisição do núcleo complexo é adquirida nas faixas etárias iniciais. A aquisição dos arquifonemas /N/, /1/, /S/ e /R/ nas posições de coda final e medial começa dos 1:7 e termina aos 3:10. Já a aquisição dos encontros consonantais tautossilábicos e heterossilábicos é finalizada por volta de 5 anos de idade.

Com base no que se sabe sobre a aquisição fonológica, pretendemos, em nossa pesquisa, verificar se os padrões entoacionais produtivos em situações discursivas complexas já estão adquiridos, uma vez que as crianças já estão em processo final de aquisição da linguagem e, portanto, já adquiriram todos os segmentos e estruturas silábicas do PB.

O trabalho de Frota et al. (2015) faz parte de uma investigação maior (FROTA; PRIETO, 2015) que propôs uma descrição prosódica abrangente de nove línguas Românicas - Francês, Catalão, Friulano, Italiano, Occitano, Português, Romeno, Sardo e Espanhol - expressa pela estrutura Métrica Autossegmental da Fonologia Entoacional, utilizando-se do sistema ToBI de transcrição. Dessa forma, a meta dos autores foi descrever o sistema prosódico de cada uma das línguas, de forma que o mesmo pudesse, facilmente, ser comparado a outras línguas Românicas. $\mathrm{O}$ livro originado do trabalho desta investigação - Intonation in Romance - oferece, não apenas uma descrição unificada da entoação e do fraseamento de diversas línguas românicas, mas também esforça-se por abranger uma considerável variação dialetal dentro das referidas línguas.

Os autores utilizaram, em seu trabalho, o método Discourse Completion Task (DCT) - um método indutivo de elicitação de dados, no qual o pesquisador apresenta uma série de situações cotidianas ao informante para, então, propor a ele que responda de acordo. Tal método, utilizado também em nosso trabalho, permite ao pesquisador controlar a informação de pano de fundo do contexto/discurso, além de sentidos pragmáticos específicos através dos enunciados proferidos e de seus contornos entoacionais. O questionário utilizado por Frota e colegas (2015) era constituído por 31 tipos frásicos, em diferentes contextos discursivos, os quais objetivavam elicitar diferentes tipos de sentença (declara- 
tivas, perguntas, comandos, pedidos e vocativos), selecionadas a partir do questionário DCT maior, desenvolvido para o Catalão (PRIETO; CABRÉ, 2007-2012) e traduzido pelos vários grupos de pesquisadores das línguas Românicas.

Um dos grandes objetivos do trabalho é o de destacar os contrastes existentes entre as Línguas Românicas, como traços upstep, downstep e de alinhamento dos tons $\mathrm{H}$, os quais só foram incorporados em situações em que são contrastivos no sistema. As autoras chamam a atenção, por outro lado, para o fato de que, uma vez que os efeitos sintagmáticos da cadeia de pitch possam ser considerados por fatores não-fonológicos, eles não foram incorporados à transcrição fonológica.

No capítulo 7 de seu livro, que é a base de nosso estudo, Frota e colegas (2015) oferecem uma primeira análise prosódica do ToBI da Língua Portuguesa, considerando a variação entoacional de quatro variedades do Português Brasileiro e quatro variedades do Português Europeu.

O questionário utilizado em nosso estudo é, com adaptações, o mesmo inquérito utilizado no estudo de Frota e colegas (2015). Focamos, como se pode verificar, os seguintes tipos frásicos: declarativas neutras; declarativas neutras com enumeração; declarativas não neutras dos tipos focalização contrastiva e exclamativa; interrogativas absolutas neutras dos tipos disjunção e disjunção com enumeração; interrogativas absolutas não neutras dos tipos pergunta confirmatória e pergunta imperativa; interrogativa parcial neutra com oração de uma unidade tonal; imperativa do tipo ordem; e vocativos.

\section{Metodologia de Pesquisa ${ }^{1}$}

Os dados empíricos para esta investigação são os dados coletados pelo método DCT, a partir da fala de três crianças, as quais foram gravadas para posterior análise de seu sistema entoacional. As três crianças são brasileiras, duas do sexo feminino, com 5 anos e 9 meses e 6 anos e 8 meses, e uma do sexo masculino, com 6 anos e 6 meses. Para a realização do experimento, houve permissão por escrito de seus pais. As gravações foram realizadas na casa das crianças, com um gravador Sony PCM-D50 que apresenta dois microfones direcionais. As crianças se mostraram espontâneas e pareceram estar à vontade diante do aparelho.

Com base no questionário de Frota et al. (2015), selecionamos 16 tipos frásicos que foram propostos a criança por meio de diferentes situações discursivas: 3 declarativas neutras, 2 enumerações, 1 focalização contrastiva, 1 exclamativa, 1 pergunta disjuntiva

\footnotetext{
${ }^{1}$ Esta pesquisa está coberta pelo CAAE 26935114.8.0000.5147, aprovado pelo Comitê de Ética da UFJF. Os responsáveis pelas crianças assinaram o Termo de Consentimento Livre e Esclarecido (TCLE).
} 
- sim ou não, 1 enumeração com disjunção, 1 pergunta confirmatória, 2 perguntas imperativas, 1 entoação imperativa de ordem, 1 entoação imperativa de pedido e 2 vocativos.

As examinadoras apresentavam para a criança uma imagem ou descreviam uma situação que estimulasse a criança a produzir uma determinada sentença para cada tipo frásico citado no parágrafo anterior. Como exemplo, apresentamos abaixo a figura e o contexto para a elicitação da sentença declarativa neutra "O galã anda de porsche":

Figura 1. Exemplo de um item do questionário utilizado nas gravações Este é o galã da novela. Diz que o galã anda de porsche.

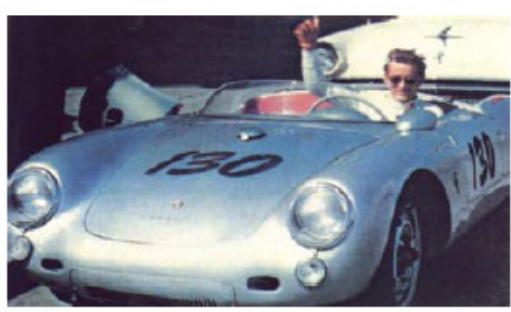

O galã anda de porsche

As gravações foram, então, segmentadas fala-a-fala para que os dados do discurso fossem transcritos ortográfica e foneticamente, bem como analisados prosodicamente. $\mathrm{O}$ software PRAAT (BOERSMA; WEENIK, 2008) foi utilizado para cada arquivo segmentado e posterior análise prosódica. Para cada arquivo de áudio, a análise prosódica incluiu uma camada tonal e uma camada com a transcrição ortográfica da sentença.

As examinadoras, diante das crianças, se esforçaram por tornar o ambiente o mais calmo e silencioso possível. A cada situação, era oferecido um apoio à criança, no sentido de elucidar possíveis dúvidas, sem que, no entanto, a frase esperada fosse proferida pelas examinadoras, isso para que o experimento não fosse comprometido.

Pela pouca idade, as crianças tiveram mais dificuldade com algumas situações, especialmente quando era necessário que elas se imaginassem em determinado lugar, ou diante de uma situação que lhes era incomum.

\section{Resultados e análises}

Após a coleta de dados, realizamos as análises acústicas de cada item para podermos comparar com as generalizações feitas em Frota et al. (2015) para o padrão entoacional da variedade mineira do PB.

As sentenças declarativas neutras (broad focus statements), segundo os autores, apresentam um contorno nuclear do tipo $\mathrm{H}+\mathrm{L}^{*} \mathrm{~L} \%$, caracterizado por uma subida na sílaba pretônica $\mathrm{H}$ e por queda na sílaba tônica $\mathrm{L}^{*}$ que se estenderá até o final do enunciado $\mathrm{L} \%$. 
Em Frota et al. (2015), esse contorno entoacional se sustentou em todas as variedades do PB. Em nossos dados de fala, também encontramos o mesmo padrão entoacional para esse tipo de frase, indicando que as crianças envolvidas em nosso estudo já utilizam esse tipo de padrão tonal em sua fala. Apresentamos abaixo os espectrogramas das sentenças produzidas pelas crianças de 5:9 anos (Figura 2), de 6:6 anos (Figura 3) e de 6:8 anos (Figura 4):

Figura 2. Espectrograma da sentença declarativa neutra “O galã anda de porsche.” produzida pela criança de 5 anos e 9 meses

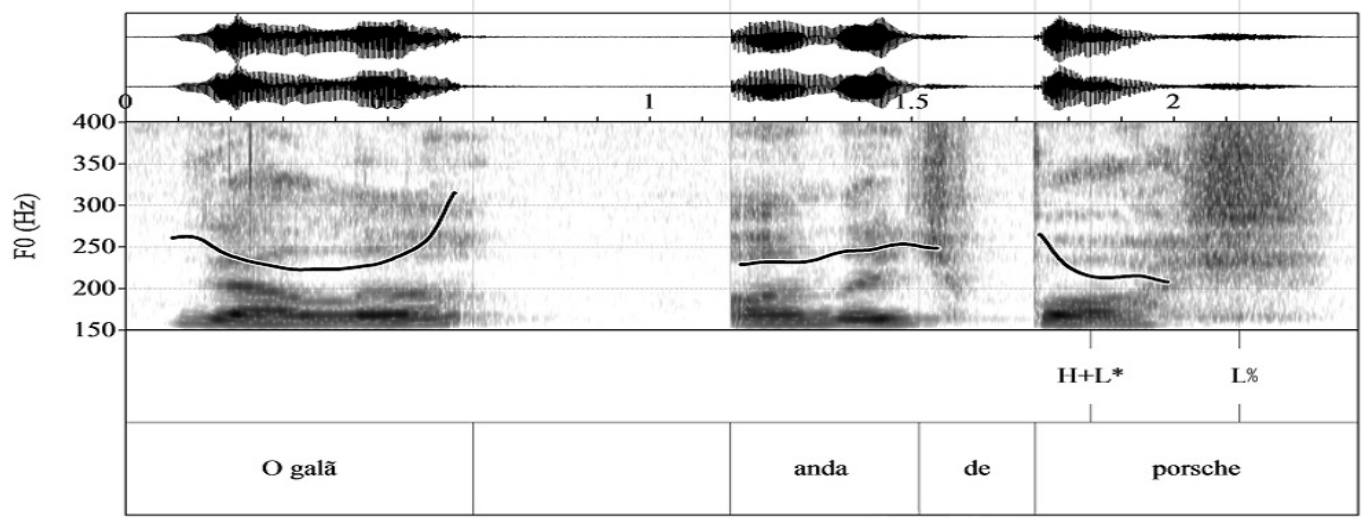

Na sentença produzida pela criança de 5:9 anos (Figura 2), apesar de haver uma pausa entre o sujeito ( $\mathrm{g}$ galã) e o verbo ( $a$ nda $)$, não há marcas acústicas de alongamento que caracterize esse DP como um I independente. Portanto, o espectrograma sugere que houve focalização não contrastiva no sujeito.

Figura 3. Espectrograma da sentença declarativa neutra "Ele anda de porsche" produzida pela criança de 6 anos e 6 meses.

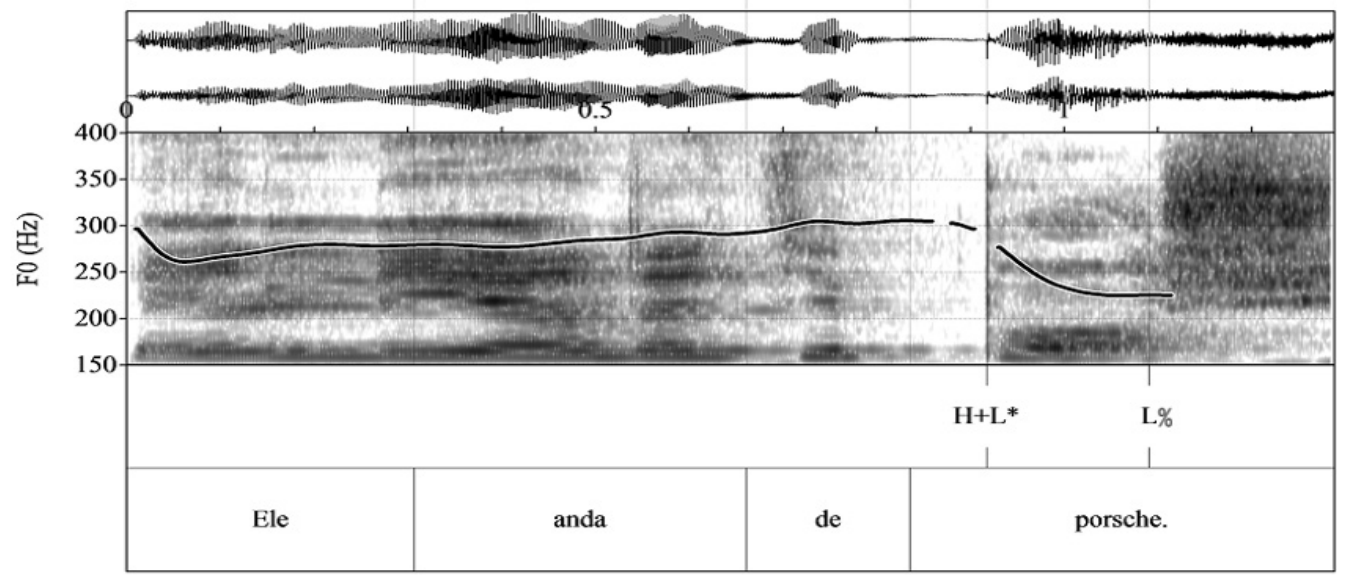


Figura 4. Espectrograma da sentença declarativa neutra "O galã anda de porsche." produzida pela criança de 6 anos e 8 meses.

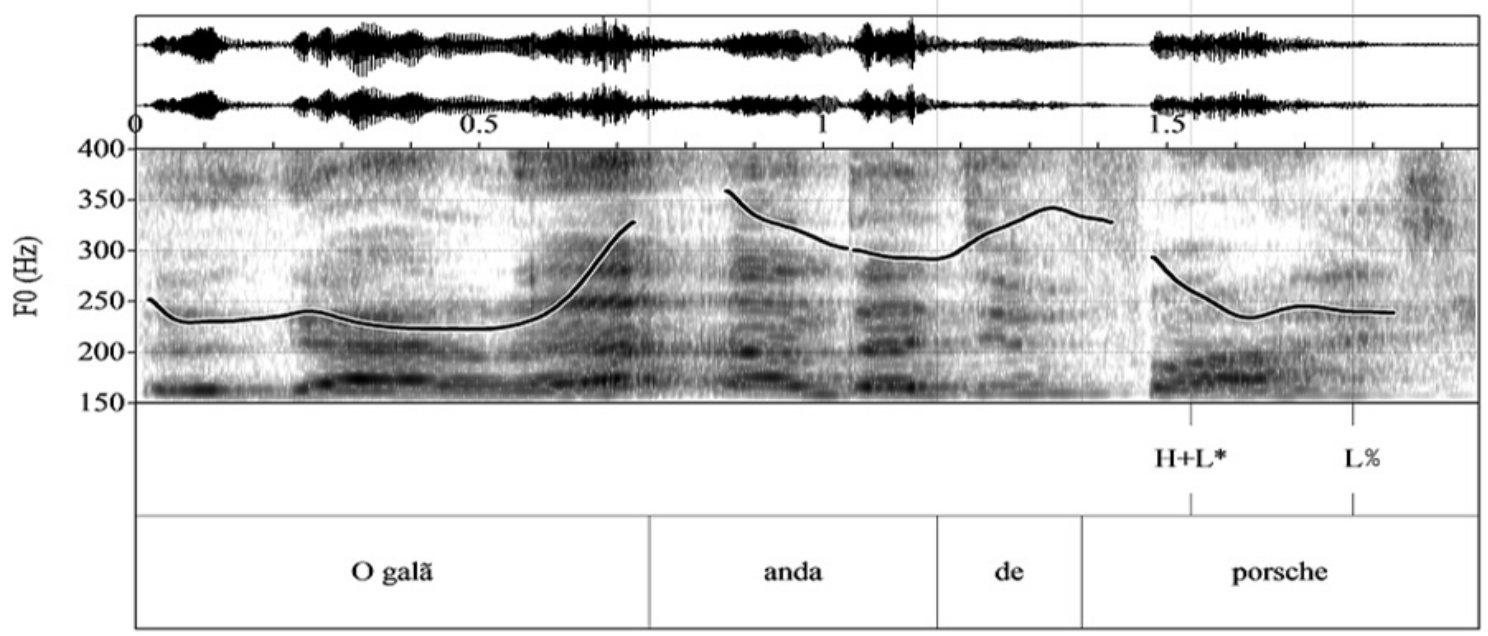

A produção da criança de 6:6 anos (Figura 3) possui um contorno entoacional inicial diferente das produções das crianças de 5:9 anos (Figura 2) e 6:8 anos (Figura 4) devido ao fato de a criança ter produzido o pronome ele em vez de o substantivo o galã. No entanto, essa diferença inicial não nos parece influenciar a produção do acento tonal final da sentença.

De acordo com Frota et al. (2015), sentenças declarativas neutras (broad focus statements) contrastam com sentenças declarativas não neutras com focalização contrastiva (narrow focus statements), nas quais ocorre o uso pragmático da focalização de um determinado constituinte, como forma de correção de uma interpretação relacionada a um enunciado anterior. Vejamos o exemplo (1).

(1) Entrevistador: E então? O que aconteceu com os donos do restaurante? Separaram-se?

Criança: Eles se casaram.

Para a variedade mineira do PB, Frota et al. (2015) descreve um tom baixo L na pretônica e uma subida $\mathrm{H}^{*}$ na sílaba tônica seguido de um tom de fronteira baixo L\%, resultando em um contorno entoacional do tipo $\mathrm{L}+\mathrm{H}^{*} \mathrm{~L} \%$. Com relação aos nossos dados de fala, somente a criança de 6:6 anos atingiu esse padrão. A criança de 5:9 anos não conseguiu produzir uma sentença para essa situação conversacional, e a criança de 6:8 anos produziu uma sentença com padrão entoacional semelhante ao da sentença declarativa 
neutra. $\mathrm{O}$ contorno entoacional apresentou um tom downstep na pretônica !H seguido de uma descida na sílaba tônica $L^{*}$, com tom fronteira final baixo L\%. Para nós, tal resultado pode ser justificado pelo fato de essas duas crianças ainda não possuírem esse contorno entoacional em sua fala, ou pelo fato de a situação não ter sido clara o suficiente para elucidar tal contorno.

Com relação às sentenças exclamativas, que também são caracterizadas como declarativas não neutras, os autores encontraram para a variedade mineira, na frase "Ai, que cheirinho bom de pão", o tom baixo L na sílaba pretônica seguido de um tom alto $\mathrm{H}^{*}$ na sílaba tônica, com tom fronteira final alto $\mathrm{H} \%$. Em nossos dados de fala, encontramos o mesmo padrão entoacional típico de sentenças declarativas neutras, $\mathrm{H}+\mathrm{L}^{*} \mathrm{~L} \%$. Somente as crianças de 5:9 anos e 6:8 anos conseguiram produzir sentenças para essa situação conversacional.

Segundo Frota e colaboradores (2015), interrogativas absolutas neutras (yes-no questions - information seeking) são aquelas nas quais o falante busca saber uma informação que lhe é desconhecida. Esse tipo de pergunta desencadeia uma resposta "sim" ou "não" por parte do interlocutor. Para o presente estudo, selecionamos interrogativas absolutas neutras do tipo disjunção, como no exemplo (2), e enumeração com disjunção, como no exemplo (3).

(2) Você quer laranja ou gelatina?

(3) Você quer laranjas, bananas, limões ou peras?

$\mathrm{Na}$ interrogativa absoluta neutra do tipo disjunção, foi encontrado no sintagma entoacional intermediário um acento tonal $\mathrm{L}+\mathrm{H}^{*}$ seguido de um tom fronteira downstep $! \mathrm{H} \%$, enquanto que no sintagma entoacional final encontrou-se um acento tonal $\mathrm{H}+\mathrm{L}^{*}$ seguido de um tom de fronteira $\mathrm{L} \%$. Na interrogativa absoluta neutra do tipo disjunção com enumeração, foi encontrado nos sintagmas entoacionais intermediários um acento tonal $\mathrm{L}+\mathrm{H}^{*}$ seguido de um tom fronteira $\mathrm{H} \%$, enquanto que no sintagma entoacional final encontrou-se um acento tonal $\mathrm{H}+\mathrm{L}^{*}$ seguido de um tom de fronteira $\mathrm{L} \%$. Comparandose esses padrões entoacionais com os nossos dados, encontramos o mesmo resultado para a fala das três crianças, como pode ser visto nas figuras 5, 6 e 7. Na fala das crianças de 5:9 anos (Figura 5) e de 6:8 anos (Figura 7), encontramos ainda um acento tonal de início de frase $\mathrm{H}+\mathrm{L}^{*}$. 
Figura 5. Espectrograma da sentença interrogativa absoluta neutra com disjunção “Você quer laranja ou gelatina?" produzida pela criança de 5 anos e 9 meses.

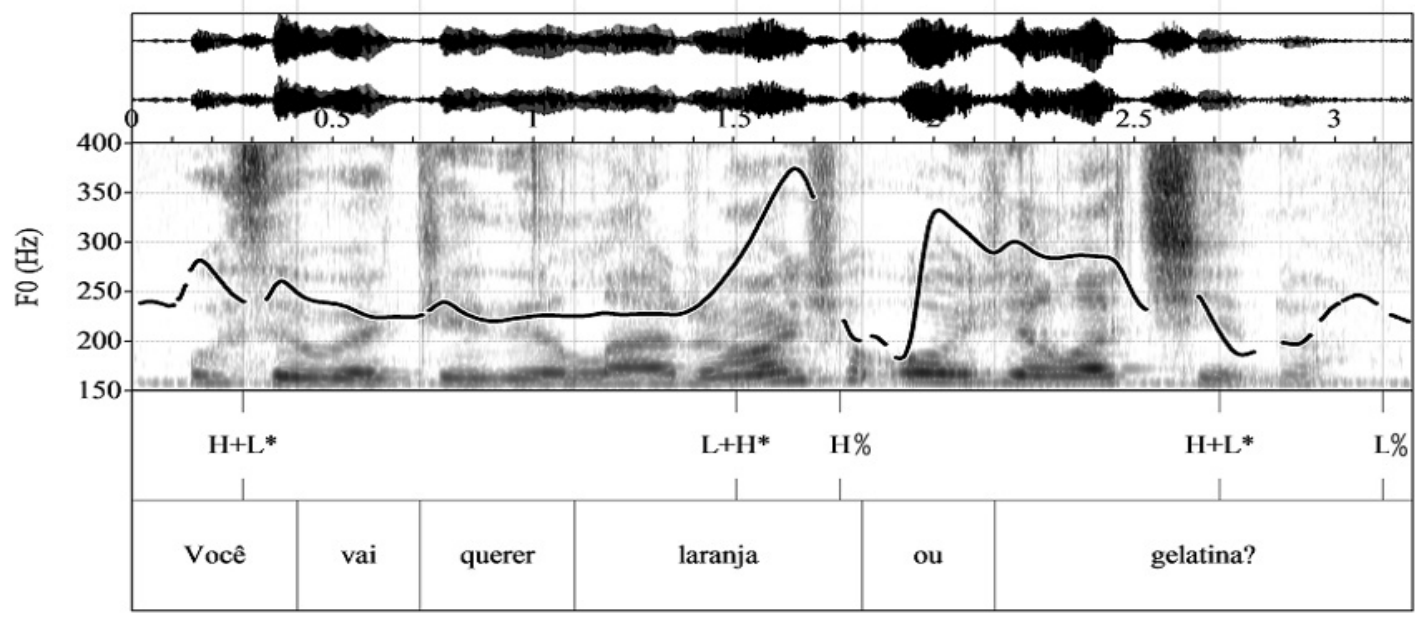

Figura 6. Espectrograma da sentença interrogativa absoluta neutra com disjunção “Você quer laranja ou gelatina?" produzida pela criança de 6 anos e 6 meses.

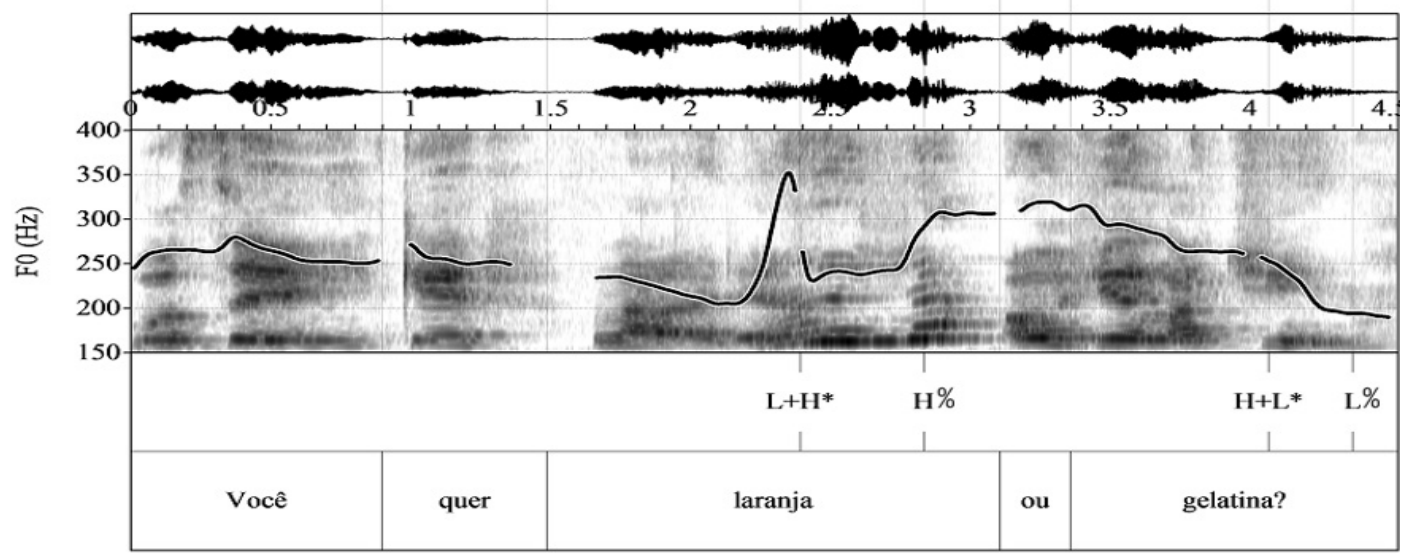

Figura 7. Espectrograma da sentença interrogativa absoluta neutra com disjunção “Você quer laranja ou gelatina?" produzida pela criança de 6 anos e 8 meses.

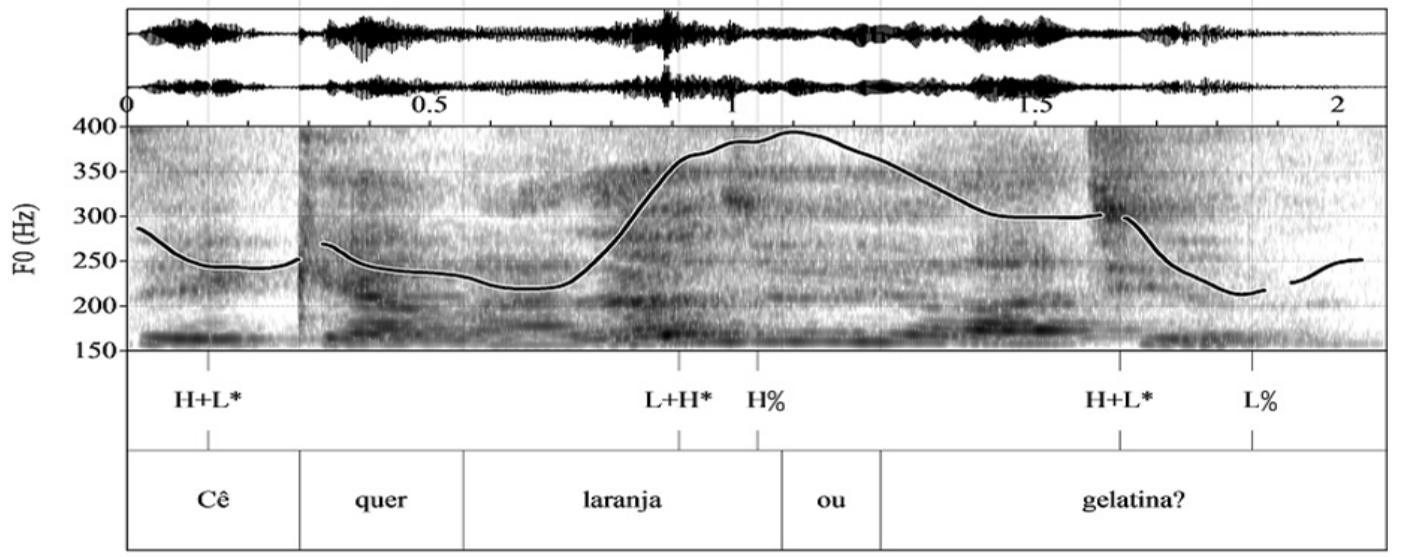


Vale ressaltar que esses resultados também vão ao encontro do que é defendido por Nespor e Vogel (1986), de que a enumeração de itens, que gera um efeito lista, confere uma reestruturação dos sintagmas entoacionais, os quais terão um contorno entoacional próprio.

De acordo com os autores, sentenças interrogativas absolutas do tipo confirmatória (yes-no questions - confirmation seeking) são consideradas não neutras e são aquelas nas quais a informação já é compartilhada tanto pelo falante, quanto pelo interlocutor. O falante, então, faz esse tipo de pergunta no intuito de confirmar com o interlocutor a informação que ambos já sabem. Os pesquisadores encontraram para a sentença " $L a ́$ fora tá frio?", na variedade mineira do adulto, um acento tonal do tipo $\mathrm{L}^{*}+\mathrm{H}$ seguido de um tom fronteira $\mathrm{L} \%$. Já em nossos dados, encontramos um acento tonal $\mathrm{L}+\mathrm{H}^{*}$ seguido de um tom fronteira $\mathrm{L} \%$ na fala da criança de 6:6 anos (Figura 8) e o padrão $\mathrm{L}+\mathrm{H}^{*} \mathrm{H} \%$ na fala da criança de 6:8 anos (Figura 9). Os autores consideram o aparecimento de um acento tonal de cauda pelo fato de a sílaba pretônica "tá" ser uma sílaba tônica. Apesar de estarmos diante da mesma situação - a sílaba pretônica "lá" também é uma sílaba tônica - em nossos dados, seguiremos a proposta de Moraes (2007), de que o PB não apresenta acento de cauda.

Figura 8. Espectrograma da sentença interrogativa absoluta não neutra pergunta confirmatória “Tá frio lá fora?” produzida pela criança de 6 anos e 6 meses.

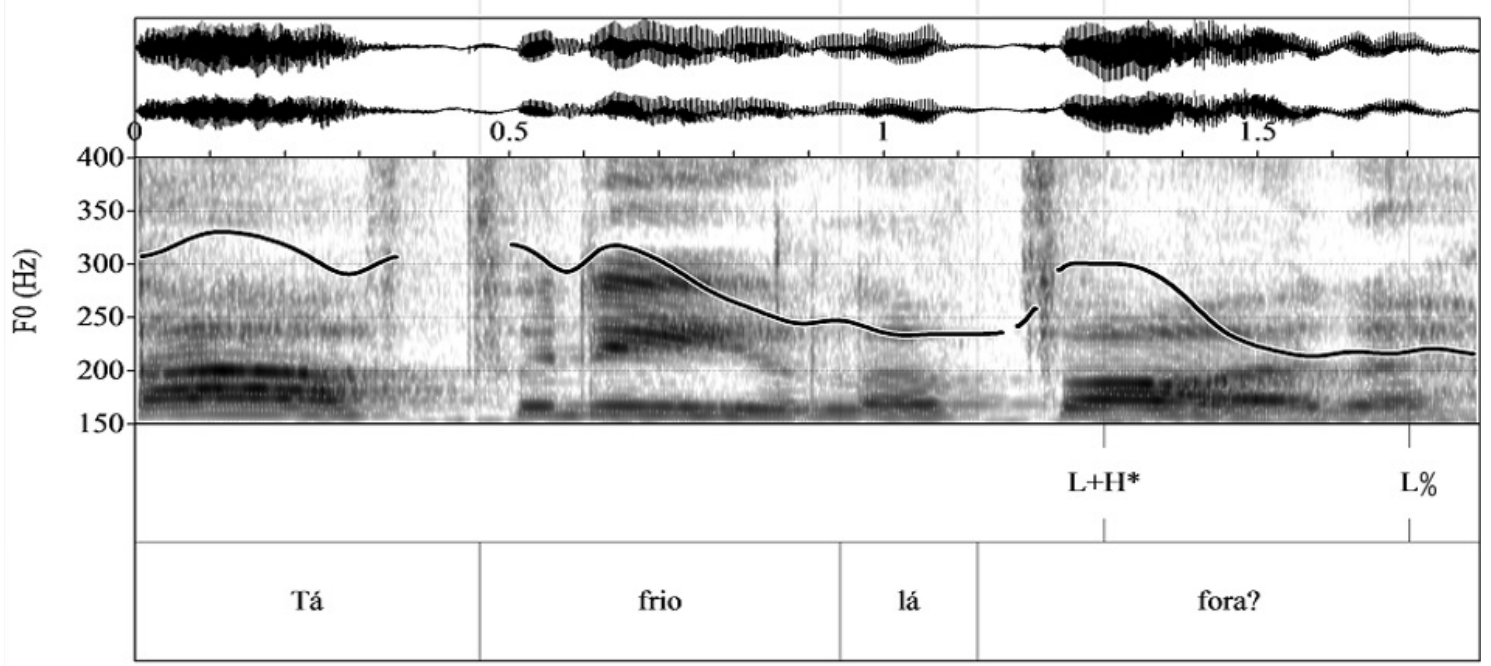


Figura 9. Espectrograma da sentença interrogativa absoluta não neutra pergunta confirmatória “Tá frio?” produzida pela criança de 6 anos e 8 meses.

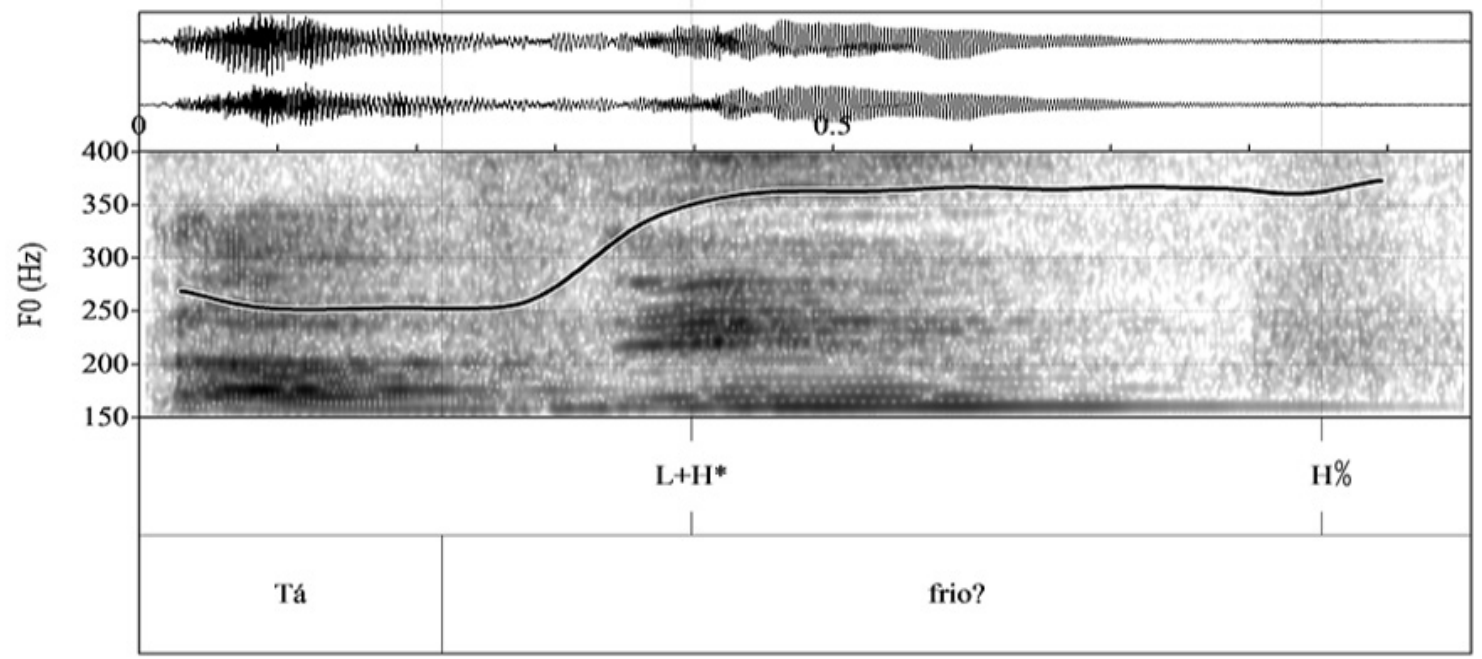

Com relação à diferença entre os tons fronteira encontrados nas produções das crianças de 6:6 anos (Figura 8) e 6:8 anos (Figura 9), acreditamos que foi influenciada pela diferença sintática das sentenças produzidas. A sentença da criança de 6:8 anos (Figura 9) é curta em comparação com a sentença produzida pela criança de 6:6 anos (Figura 8) e, portanto, possui menos espaço fonético para maiores modulações entoacionais. Este fato motivou a permanência do tom alto entre o acento tonal $\left(\mathrm{L}+\mathrm{H}^{*}\right)$ e a fronteira final (H\%) na sentença produzida pela criança de 6:8 anos (Figura 9).

Conforme apontam Frota et al. (2015), sentenças interrogativas parciais (wh-questions) caracterizam-se por conter uma palavra (question word) que evidencia que a sentença é uma pergunta e especifica o foco da questão. No português, essas palavras geralmente aparecem no início de frase. Nesse tipo de interrogativa, o falante busca uma informação que lhe é desconhecida e que, ao mesmo tempo, é identificada pela question word. Em seus dados, os autores encontraram o mesmo contorno entoacional observado para as sentenças declarativas neutras, $\mathrm{H}+\mathrm{L}^{*} \mathrm{~L} \%$. Já em nossos dados, pudemos observar este resultado na fala da criança de 6:6 anos (Figura 10). A criança de 6:8 anos (Figura 11) produziu um padrão $H^{*}+L$ L e a criança de 5:9 anos não conseguiu produzir nenhuma sentença. 
Figura 10. Espectrograma da sentença interrogativa parcial neutra

Que horas são?" produzida pela criança de 6 anos e 6 meses.

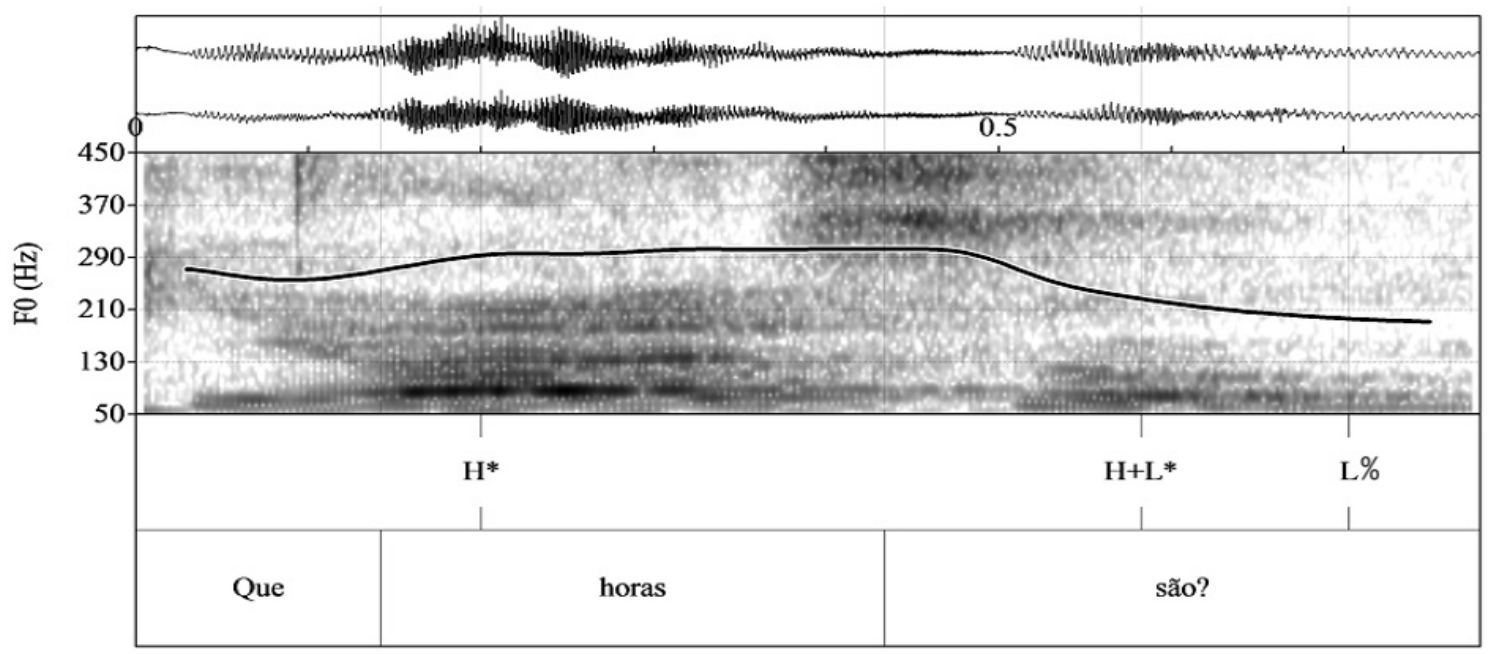

Figura 11. Espectrograma da sentença interrogativa parcial neutra

“Que horas são?" produzida pela criança de 6 anos e 8 meses.

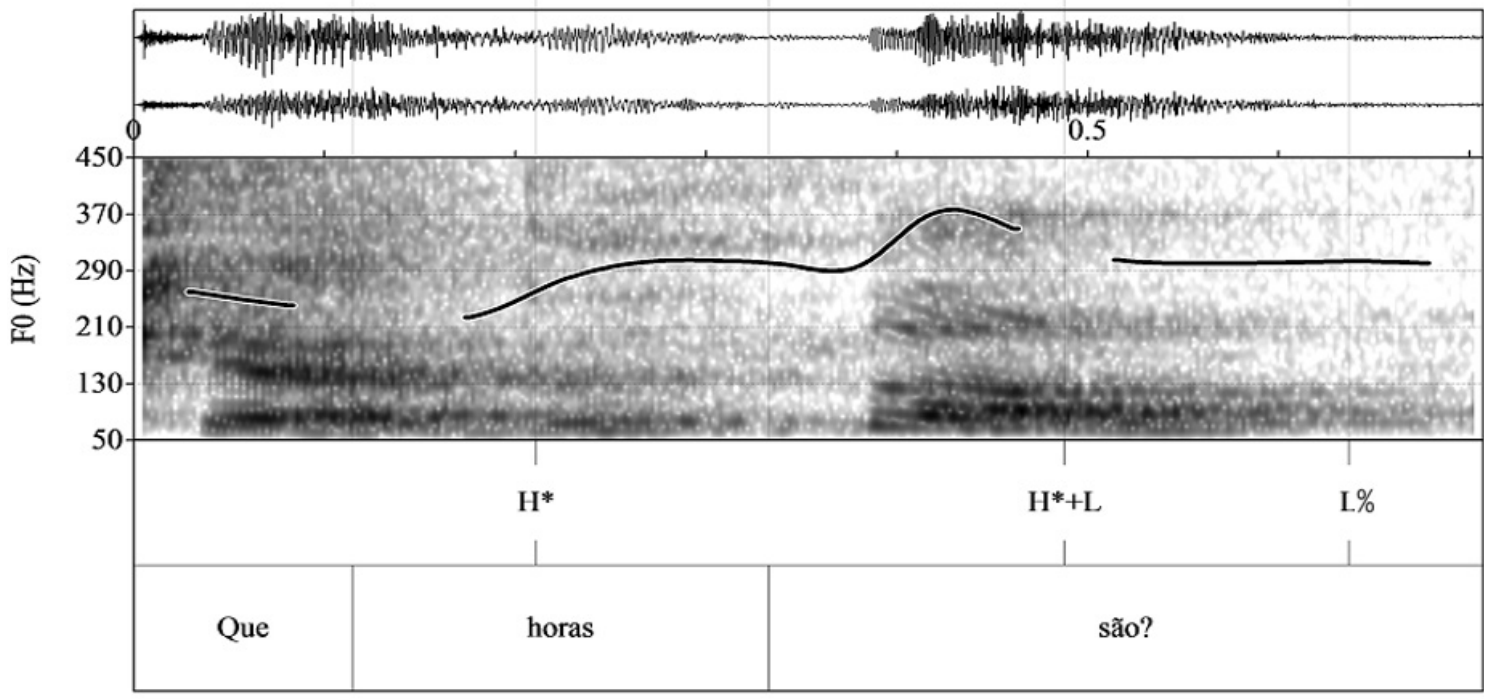

No que tange às sentenças imperativas, Frota et al. (2015) apontam que elas são geralmente iniciadas por um verbo que aparece na segunda pessoa. Elas podem ser utilizadas para expressar diferentes valores pragmáticos, como comando ou pedido. Na imperativa de comando, os autores encontraram para a variedade mineira, na frase "Vem cá, volta aqui!", o padrão entoacional $\mathrm{L}+\mathrm{H}^{*} \mathrm{H}^{*}+\mathrm{L} \mathrm{L} \%$ nos dois sintagmas intermediários (I). Em nossos dados, encontramos padrões diferentes. A criança de 5:9 anos não conseguiu produzir uma frase para esse contexto. A criança de 6:6 anos (Figura 12) produziu duas sentenças, “Não vá pra longe não!" com um $\mathrm{H}^{*}$ inicial seguido de um acento tonal $\mathrm{L}+\mathrm{H}^{*}$ 
$\mathrm{L} \%$ e "Vem pra cá" com um $\mathrm{LH}^{*}$ inicial e um acento tonal $\mathrm{H}+\mathrm{L}^{*} \mathrm{~L} \%$, contorno entoacional este muito próximo do padrão adulto. Já a criança de 6:8 anos (Figura 13) produziu para a frase o contorno $\mathrm{L}+\mathrm{H}^{*} \mathrm{~L} \%$.

Figura 12. Espectrograma da sentença imperativa

“Não vá pra longe, não! Vem pra cá!" produzida pela criança de 6 anos e 6 meses.

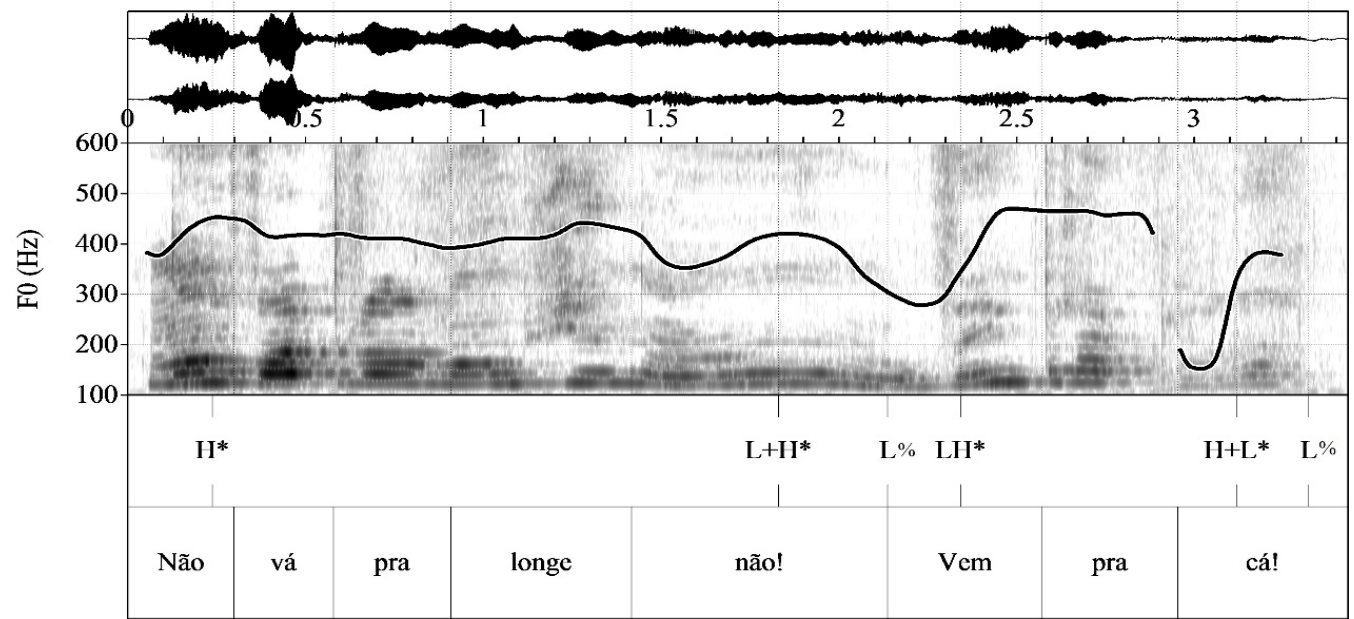

Figura 13. Espectrograma da sentença imperativa

“Vem perto de mim!" produzida pela criança de 6 anos e 8 meses.

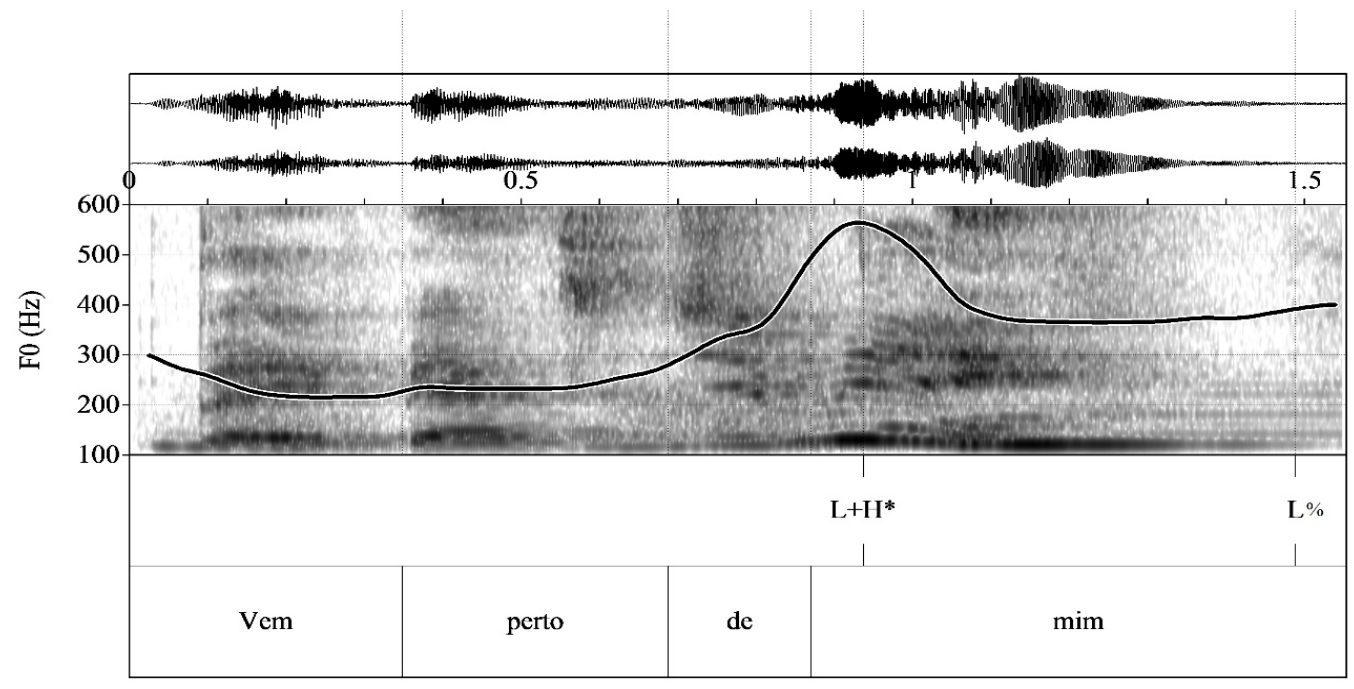

Por fim, os autores apresentam dois tipos de vocativos, sendo o primeiro um chamamento inicial (greeting call) - aquele no qual o falante chama pela primeira vez o seu 
interlocutor - e o segundo um chamamento insistente (insistent call) - aquele no qual o falante, não tendo obtido anteriormente uma resposta de seu interlocutor, o chama novamente, como em (4) e (5) abaixo.

(4) Entrevistador: Você quer que a Marina venha jantar. Chame-a. Participante: Marina!

(5) Entrevistador: Marina está demorando muito. Chame-a de novo. Participante: Mariiiinaa!!!

Na variedade mineira, para o chamamento inicial, representado em (4), os autores encontraram um acento tonal $\mathrm{L}+\mathrm{H}^{*}$ seguido de um tom fronteira downstep $\mathrm{H} \%$. Na fala da criança de 5:9 anos (Figura 14), encontramos o padrão $\mathrm{L}+\mathrm{H}^{*}$ seguido de tom fronteira baixo L\%. Medimos também a duração das sílabas: a pretônica teve duração de 196ms, a tônica $250 \mathrm{~ms}$ e a postônica $201 \mathrm{~ms}$. Na fala da criança de 6:6 anos (Figura 15), encontramos o padrão $\mathrm{L}+\mathrm{H}^{*}$ seguido de tom fronteira alto $\mathrm{H} \%$. Quanto à duração das sílabas, a pretônica teve duração de $277 \mathrm{~ms}$, a tônica $372 \mathrm{~ms}$ e a postônica $185 \mathrm{~ms}$. Na fala da criança de 6:8 anos (Figura 16), encontramos o padrão $\mathrm{L}+\mathrm{H}^{*}$ seguido de tom fronteira baixo L\%. Quanto à duração das sílabas, a pretônica teve duração de $257 \mathrm{~ms}$, a tônica $244 \mathrm{~ms}$ e a postônica $279 \mathrm{~ms}$.

Já para o chamamento insistente, representado em (5), os pesquisadores encontraram um acento tonal $\mathrm{L}+\mathrm{H}^{*}$ seguido de um tom fronteira $\mathrm{L} \%$. Encontramos o mesmo padrão entoacional na fala das crianças de 5:9 anos e 6:8 anos. Medimos também a duração das sílabas, sendo que na fala da criança de 5:9 encontramos os seguintes valores: a pretônica teve duração de $275 \mathrm{~ms}$, a tônica $253 \mathrm{~ms}$ e a postônica $279 \mathrm{~ms}$. Diferentemente da produção do chamamento inicial, há um alongamento da postônica no chamamento insistente, a criança de 5:9 anos usa a entoação para diferenciar entre os dois tipos chamamentos. Quanto à duração das sílabas na fala da criança de 6:8 anos, a pretônica teve duração de $421 \mathrm{~ms}$, a tônica $261 \mathrm{~ms}$ e a postônica $316 \mathrm{~ms}$. A criança de 6:8 anos também emprega uma entoação para diferenciar entre os dois chamamentos, visto que dessa vez há alongamento das sílabas pretônica e postônica. Na fala da criança de 6:6 anos, encontramos um downstep $\mathrm{H}$ ! seguido de fronteira baixa L\%. Encontramos os seguintes valores de duração das sílabas: a pretônica teve duração de $363 \mathrm{~ms}$, a tônica durou $482 \mathrm{~ms}$ e a postônica durou 320ms. Apesar de o padrão entoacional não ser o mesmo padrão do falante adulto, há alongamento de todas sílabas para indicar a diferença entre os dois chamamentos. 
Figura 14. Espectrograma do chamamento insistente

“Marina!" produzido pela criança de 5 anos e 9 meses.

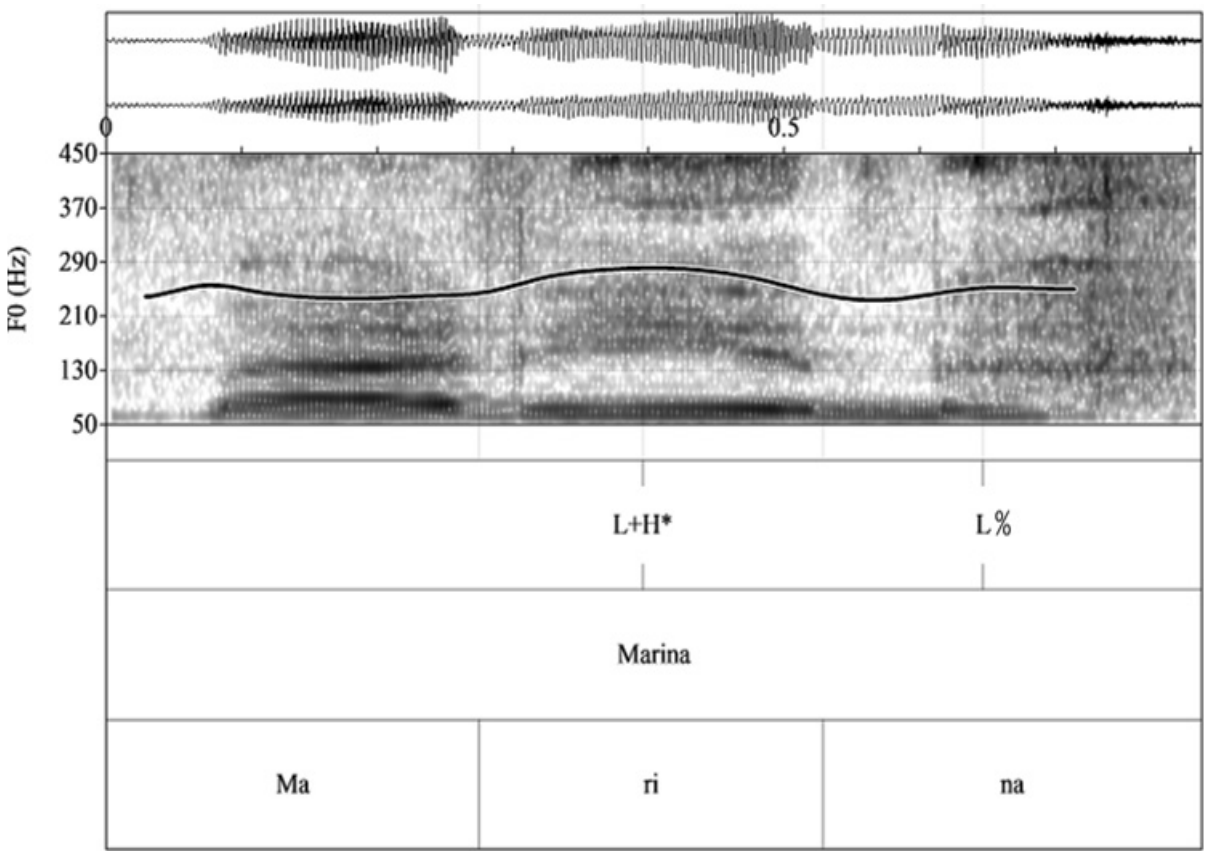

Figura 15. Espectrograma do chamamento insistente

“Marina!" produzido pela criança de 6 anos e 6 meses.

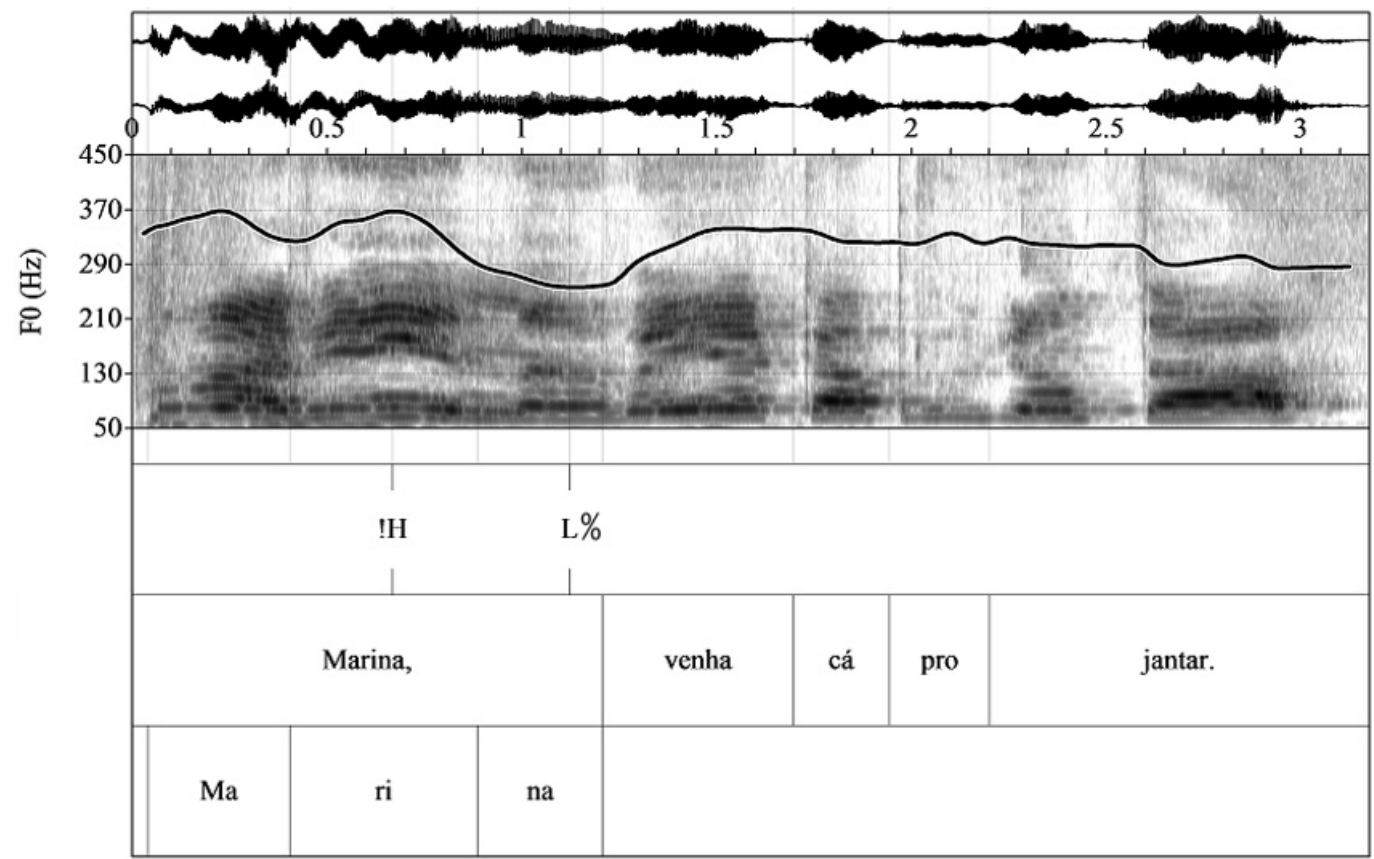

Figura 16. Espectrograma do chamamento insistente

“Marina!" produzido pela criança de 6 anos e 8 meses. 


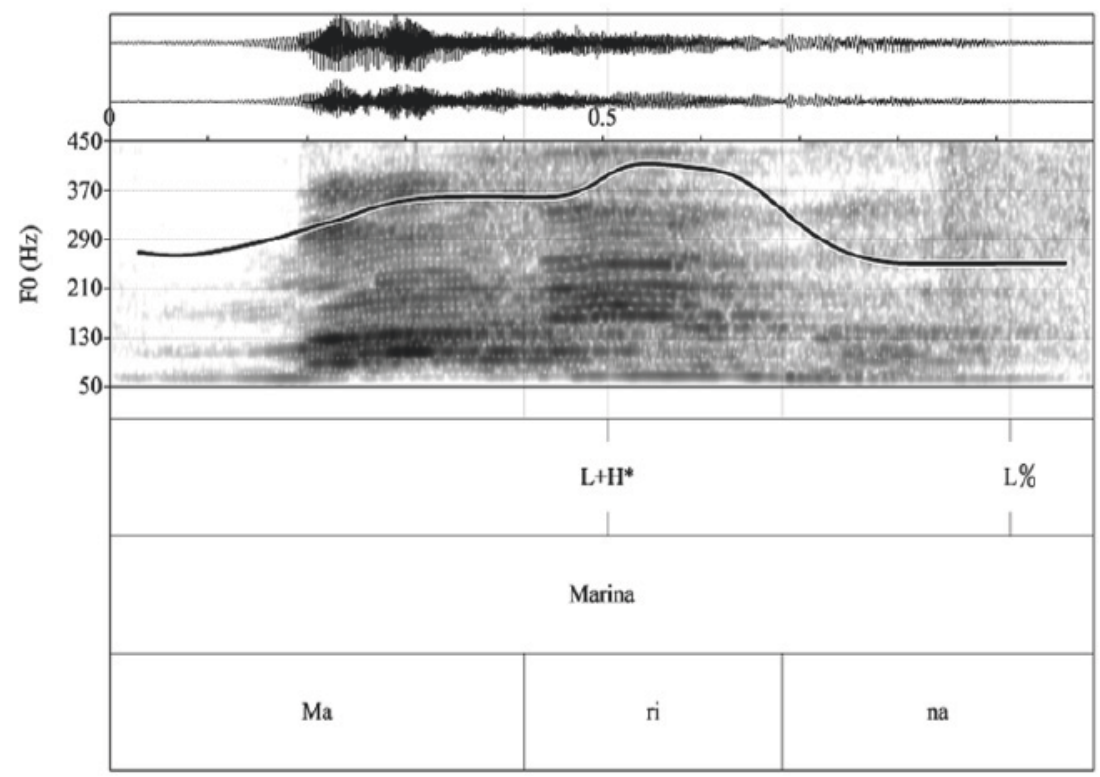

Apresentamos abaixo uma tabela ${ }^{2}$ com os tipos frásicos testados e os contornos prosódicos das três crianças em comparação com os contornos prosódicos do adulto mineiro, testado em Frota et al. (2015):

Tabela 1. Tipos frásicos testados

\begin{tabular}{|c|c|c|c|c|}
\hline $\begin{array}{c}\text { Tipos frásicos } \\
\text { testados }\end{array}$ & $\begin{array}{c}\text { Criança de } \\
5 \text { anos e } 9 \\
\text { meses }\end{array}$ & $\begin{array}{l}\text { Criança de } \\
6 \text { anos e } 6 \\
\text { meses }\end{array}$ & $\begin{array}{c}\text { Criança de } \\
6 \text { anos e } 8 \\
\text { meses }\end{array}$ & $\begin{array}{c}\text { Adulto } \\
\text { (FROTA et } \\
\text { al., 2015) }\end{array}$ \\
\hline Declarativa Neutra & $\mathrm{H}+\mathrm{L}^{*} \mathrm{~L} \%$ & $\mathrm{H}+\mathrm{L}^{*} \mathrm{~L} \%$ & $\mathrm{H}+\mathrm{L}^{*} \mathrm{~L} \%$ & $\mathrm{H}+\mathrm{L}^{*} \mathrm{~L} \%$ \\
\hline $\begin{array}{c}\text { Declarativa Neutra - } \\
\text { Enumeração }\end{array}$ & $\begin{array}{l}\mathrm{H}+\mathrm{L}^{*} \mathrm{H} \% \\
\mathrm{H}+\mathrm{L}^{*} \mathrm{~L} \%\end{array}$ & $\begin{array}{l}\mathrm{H}+\mathrm{L}^{*} \mathrm{H} \% \\
\mathrm{H}+\mathrm{L}^{*} \mathrm{~L} \% \\
\end{array}$ & $\begin{array}{l}\mathrm{H}+\mathrm{L}^{*} \mathrm{H} \% \\
\mathrm{H}+\mathrm{L}^{*} \mathrm{~L} \%\end{array}$ & $\begin{array}{l}\mathrm{H}+\mathrm{L}^{*} \mathrm{H} \% \\
\mathrm{H}+\mathrm{L}^{*} \mathrm{~L} \% \\
\end{array}$ \\
\hline $\begin{array}{l}\text { Focalização } \\
\text { Contrastiva }\end{array}$ & 8 & $\mathrm{~L}+\mathrm{H}^{*} \mathrm{~L} \%$ & $\mathrm{H} !+\mathrm{L}^{*} \mathrm{~L} \%$ & $\mathrm{~L}+<\mathrm{H}^{*} \mathrm{~L} \%$ \\
\hline Exclamativa & $\mathrm{H}+\mathrm{L}^{*} \mathrm{H} \%$ & $\otimes$ & $\mathrm{H}^{*}+\mathrm{L} \mathrm{L} \%$ & $\mathrm{~L}+\mathrm{H}^{*} \mathrm{H} \%$ \\
\hline $\begin{array}{c}\text { Interrogativa } \\
\text { Absoluta Neutra: } \\
\text { Disjunção }\end{array}$ & $\begin{array}{l}\mathrm{L}+\mathrm{H}^{*} \mathrm{H} \% \\
\mathrm{H}+\mathrm{L}^{*} \mathrm{~L} \%\end{array}$ & $\begin{array}{c}\mathrm{L}+\mathrm{H}^{*} \mathrm{H} \% \\
\mathrm{H}+\mathrm{L}^{*} \mathrm{~L} \%\end{array}$ & $\begin{array}{c}\mathrm{L}+\mathrm{H}^{*} \mathrm{H} \% \\
\mathrm{H}+\mathrm{L}^{*} \mathrm{~L} \%\end{array}$ & $\begin{array}{c}\mathrm{L}+\mathrm{H}^{*} ! \mathrm{H} \% \\
\mathrm{H}+\mathrm{L}^{*} \mathrm{~L} \%\end{array}$ \\
\hline $\begin{array}{c}\text { Interrogativa } \\
\text { Absoluta Neutra: } \\
\text { Enumeração com } \\
\text { Disjunção }\end{array}$ & $\begin{array}{c}\mathrm{L}+\mathrm{H}^{*} \mathrm{H} \% \\
\mathrm{H}+\mathrm{L}^{*} \mathrm{~L} \%\end{array}$ & $\begin{array}{c}\mathrm{L}+\mathrm{H}^{*} \mathrm{H} \% \\
\mathrm{H}+\mathrm{L}^{*} \mathrm{~L} \%\end{array}$ & $\begin{array}{c}\mathrm{L}+\mathrm{H}^{*} \mathrm{H} \% \\
\mathrm{H}+\mathrm{L}^{*} \mathrm{~L} \%\end{array}$ & $\begin{array}{c}\mathrm{L}+\mathrm{H}^{*} \mathrm{H} \% \\
\mathrm{H}+\mathrm{L}^{*} \mathrm{~L} \%\end{array}$ \\
\hline $\begin{array}{c}\text { Pergunta } \\
\text { Confirmatória }\end{array}$ & 8 & $\mathrm{~L}+\mathrm{H}^{*} \mathrm{~L} \%$ & $\mathrm{~L}+\mathrm{H}^{*} \mathrm{H} \%$ & $\mathrm{~L}+\mathrm{H}^{*} \mathrm{~L} \%$ \\
\hline Pergunta Imperativa & $\mathrm{L}+\mathrm{H}^{*} \mathrm{H} \%$ & $\mathrm{~L}+\mathrm{H}^{*} \mathrm{~L} \%$ & $\mathrm{~L}+\mathrm{H}^{*} \mathrm{H} \%$ & $\mathrm{H}+\mathrm{L}^{*} \mathrm{H} \%$ \\
\hline $\begin{array}{c}\text { Interrogativa Parcial } \\
\text { Neutra }\end{array}$ & 8 & $\mathrm{H}+\mathrm{L}^{*} \mathrm{~L} \%$ & $\mathrm{H}^{*}+\mathrm{L} \mathrm{L} \%$ & $\mathrm{H}+\mathrm{L}^{*} \mathrm{~L} \%$ \\
\hline
\end{tabular}

${ }^{2} \mathrm{O}$ símbolo indica que a criança não conseguiu produzir uma sentença para o tipo frásico testado. 


\begin{tabular}{|c|c|c|c|c|}
\hline Imperativa: Ordem & $\otimes$ & $\begin{array}{c}\mathrm{LH}^{*} \\
\mathrm{H}+\mathrm{L}^{*} \mathrm{~L} \%\end{array}$ & $\mathrm{~L}+\mathrm{H}^{*} \mathrm{~L} \%$ & $\begin{array}{c}\mathrm{L}^{*}+\mathrm{H} \\
\mathrm{H}+\mathrm{L}^{*} \mathrm{~L} \%\end{array}$ \\
\hline $\begin{array}{c}\text { Vocativo: } \\
\text { Chamamento Inicial }\end{array}$ & $\mathrm{L}+\mathrm{H}^{*} \mathrm{~L} \%$ & $\mathrm{~L}+\mathrm{H}^{*} \mathrm{H} \%$ & $\mathrm{~L}+\mathrm{H}^{*} \mathrm{~L} \%$ & $\mathrm{~L}+\mathrm{H}^{*} ! \mathrm{H} \%$ \\
\hline $\begin{array}{c}\text { Vocativo: } \\
\text { Chamamento } \\
\text { Insistente }\end{array}$ & $\mathrm{L}+\mathrm{H}^{*} \mathrm{~L} \%$ & $\mathrm{H} ! \mathrm{L} \%$ & $\mathrm{~L}+\mathrm{H}^{*} \mathrm{~L} \%$ & $\mathrm{~L}+\mathrm{H}^{*} \mathrm{~L} \%$ \\
\hline
\end{tabular}

A partir de nossas análises, foi possível perceber que as três crianças conseguiram atingir o padrão entoacional adulto em enunciados com estruturas sintáticas e prosódicas mais simples, como declarativas neutras e enumerações. No entanto, em enunciados mais complexos, do ponto de vista estrutural e informacional, tais como exclamativas, imperativas, focalização contrastiva, interrogativas parciais e absolutas não neutras, houve uma gradação entre as crianças da menor para a maior idade para atingir o padrão entoacional do adulto mineiro.

\section{Conclusões}

Os resultados que apresentamos aqui são dados iniciais de uma pesquisa sobre a aquisição da prosódia de situações discursivas simuladas por crianças na fase final de aquisição da linguagem. Parece-nos que as crianças adquirem os padrões entoacionais de forma gradativa, assim como adquirem os segmentos, as palavras e as estruturas da língua: partindo do mais simples e recorrente, para o mais complexo e menos recorrente. A partir da análise dos dados coletados, pudemos perceber que todas as crianças apresentaram o padrão entoacional adulto em enunciados com estruturas sintáticas e prosódicas mais simples, tais como declarativas neutras $\left(\mathrm{H}+\mathrm{L}^{*} \mathrm{~L} \%\right)$ e enumerações $\left(\mathrm{H}+\mathrm{L}^{*} \mathrm{H} \%\right.$ para Is intermediários e $\mathrm{H}+\mathrm{L}^{*} \mathrm{~L} \%$ para o I final do enunciado). Já para os enunciados mais complexos, do ponto de vista estrutural e informacional, tais como exclamativas, imperativas, focalização contrastiva, interrogativas parciais e absolutas não neutras, notamos que houve um gradiente para atingir o padrão entoacional adulto entre as crianças da menor para a maior idade. Os resultados desta análise mostram-nos que uma maior complexidade informacional e sintática pode gerar maior complexidade do ponto de vista prosódico, fazendo com que a aquisição de padrões entoacionais pelas crianças seja escalonada de forma semelhante às escalas de aquisição fonológica dos padrões segmentais e silábicos de sua língua materna (LAMPRECHT et al., 2004).

Acreditamos que é importante expandir, futuramente, o número de sujeitos parti- 
cipantes, delimitando de forma mais precisa as faixas etárias para testarmos com maior precisão a nossa hipótese da gradiência da aquisição prosódica pela criança falante da variedade mineira do $\mathrm{PB}$.

\section{Agradecimentos}

Este trabalho foi desenvolvido no âmbito do Projeto InAPoP - Interactive Atlas of the Prosody of Portuguese (PTDC/CLE-LIN/119787/2010), financiado pela Fundação para a Ciência e a Tecnologia (Portugal).

\section{Referências}

BECKMAN, M. E.; PIERREHUMBERT, J. B. Intonational structure in Japanese and English. Phonology, 3, p. 255-309, 1986.

BOERSMA, P.; WEENICK, D. PRAAT: doing phonetics by computer (version: 5.3.22), 2008. Disponível em: http://www.praat.org/. Acesso em 02/10/2016.

CHOMSKY, N. Aspects of Theory of Syntax. Massachusetts: MIT Press, 1965.

CHRISTOPHE, A.; GUASTI, T.; NESPOR, M.; DUPOX, E.; VAN OOYEN, B. Reflections on phonological bootstrapping: its role for lexical and syntactic acquisition. Language and Cognitive Processes, v. 12, no 5/6, p. 585-612, 1997.

FONSECA, A. A. Pistas Prosódicas e o Processamento de sentenças ambíguas do tipo "SN1-V-SN2-Atributo" do Português Brasileiro. 2008. 129 fls. Dissertação (Mestrado em Linguística) - Faculdade de Letras, Universidade Federal de Minas Gerais. Belo Horizonte, 2008.

FROTA, S. Prosody and Focus in European Portuguese: Phonological Phrasing and Intonation. New York: Garland Publishing Inc, 2000.

FROTA, S.; CRUZ, M.; SVARTMAN, F.; COLLISSCHONN, G.; FONSECA, A.; SERRA, C.; OLIVEIRA, P; VIGÁRIO, M. Intonational variation in Portuguese: European and Brazilian varietes. In: FROTA, S. \& PRIETO, P. (Eds.). Intonation in Romance. Oxford: Oxford University Press, 2015. p. 235-283.

FROTA, S. \& PRIETO, P. (Eds.). Intonation in Romance. Oxford: Oxford University Press, 2015.

HIRST, D. J.; DI CRISTO, A. A survey of Intonation Systems. In: (Eds.), Intonation Systems: A Survey of Twentylanguages. Cambridge: Cambridge University Press, 1998. p. 1-44.

LAMPRECHT, R. R., BONILHA, G. F. G.; FREITAS, G. C. M.; MATZENAUER, C. L. B.; MEZZOMO, C. L.; OLIVEIRA, C. C.; RIBAS, L. P. Aquisição Fonológica do Português: Perfil de Desenvolvimento e subsídios para terapia. São Paulo: Editora ARTMED, 2004. 
MATZENAUER, C. L. B. Bases para o entendimento da aquisição fonológica. In: LAMPRECHT, R. R., BONILHA, G. F. G.; FREITAS, G. C. M.; MATZENAUER, C. L. B.; MEZZOMO, C. L.; OLIVEIRA, C. C.; RIBAS, L. P. Aquisição Fonológica do Português: Perfil de Desenvolvimento e subsídios para terapia. São Paulo: Editora ARTMED, 2004. P. 33-58.

MORAES, J. Intonational phonology of Brazilian Portuguese. ICPhS Satellite Meeting, Saarbrucken, 5/8/2007.

MORGAN, J. L.; DEMUTH, K. Signal to syntax: An overview. In: (Eds.) Signal to syntax: Bootstrapping from speech to grammar in early acquisition. Mahwah, NJ: Lawrence Erlbaum Associates Inc., 1996, p. 1-22.

NESPOR, I. \&VOGEL, M.ProsodicPhonology. Dordrecht-Holland: Foris Publication, 1986.

PIERREHUMBERT, J. The Phonology and Phonetics of English Intonation. 1980. 401 fls. Tese (Doutorado em Filosofia), Massachusetts Institute of Techonology. Cambridge, 1980.

PRIETO, P.; CABRÉ, T. (Coords.). Atles interactiu de l'entonació del català (20072012). Disponível em: http://prosodia.upf.edu/atlesentonacio/. Acesso em 02/10/2016. PRIETO, P.; BORRÀS-COMES, J.; ROSEANO, P. (Coords.). Interactive Atlas of Romance Intonation (2010-2014). Disponível em: http://prosodia.upf.edu/iari/. Acesso em 02/10/2016.

SERRA, C. A interface prosódia-sintaxe e o fraseamento prosódico no Português do Brasil. Journal of Speech Sciences, Campinas, v. 5, n. 2, p. 47-86, 2016.

TEIRA, C.; IGOA, J. M. Relaciones entre la prosodia y la sintaxis en el procesamiento de oraciones. Anuario de Psicología, Universitat de Barcelona, v. 38, n. 1, p. 45-69, 2007.

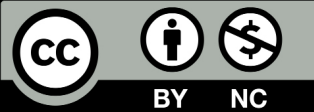

Data de submissão: 13/03/2018

Data de aceite: 16/02/2019 